\title{
THE STUDY OF MOBILE CLOUD COMPUTING:DESIGN, USES, AND METHODS
}

\author{
Prasanthi Gottumukkala ${ }^{1}$,Dr.G.Srinivasa $\mathrm{Rao}^{2}$ \\ ${ }^{1}$ Assistant Professor, CMR Engineering College, \\ ${ }^{2}$ Associate Professor, GITAM University \\ I'prasanthi.g946@gmail.com, ${ }^{2}$ giduturisrinivasarao74@gmail.com
}

\begin{abstract}
Mobile cloud computing is potential skill for mobile devices and also grownup the demand for operational availability and openness. Few years back mobile devices are used only for voice calls and text messages purposes, after value added services possible to enabled anytime and anywhere. Mobile cloud computing incorporates the mixture of both mobile also cloud computing, and solve the performance linked problems. Could Computing (CC) is integrates with usually the mobile environment moreover overcomes problems connected to the presentation (forexample: Storagespace, Bandwidth and life time of the Battery), and Environment(Accessibility, Scalability and Heterogeneity), Security. The businesses and information technology organizations and additional consumers can take the necessary facilities \& properties after cloud rapidly, effortlessly and also reasonable charges.Discussed this paper on survey Mobile cloud computing which helps forresearcher's mccdesign, methods and also uses. Problems occurred in mcc and present resolutions and methodologies used to resolve problems. For further extension of this is giving instructions to mobile cloud computing research.
\end{abstract}

Keyword: Cloud Computing, Mobile Cloud Computing, Mobile Devices, Bandwidth, Security and Mobile Services

\section{Introduction}

In this paper explore a MCC complete survey. The brief MCC overview, Mobile Could Computing definition, Design and also Benefits are discussed Part 2. In Part 3 discussed the Uses of Mobile Cloud Computing. Next, In Part4 discussed many problems in Mobile Cloud Computing and methods to report the problems. In part 5 the guidelines of futureresearch. Lastly, In Part 6 we consolidate and determine the MCC research survey. In the Table 1 describes the list of Abbreviations.

\section{MOBILE CLOUD COMPUTING EXPLANATION:}

Mobile Cloud computing term introduced before the cloud computing. It is very attracting of industrialists as a good gainful industry decisionthat decreases the improvement and consecutively price of requests of mobile, In new knowledge mobile

users use the new technology with low cost, as research persons promised the key answer for information technology. In this part presents an explanation of MCC containing meaning, Architecture, \& Also Advantages of MCC.

\section{MEANING OF MCC}

In Mobile Cloud Computing the major powerful energy is mobile computing. In global gradually increased day by day Mobile applications. 8.2 billion downloads in 2010 and rapidly increased in 2011 on 17.7 billion download, and 140.68billion apps are downloaded in 2016 and 192.45 billion apps are downloaded in 2018 and finally In 2019 as per research records 204 billion apps are customers downloaded. 


\begin{tabular}{|l|l|}
\hline Year & $\begin{array}{l}\text { Annual Downloaded Apps } \\
\text { in billions }\end{array}$ \\
\hline 2010 & 8.2 \\
\hline 2011 & 17.7 \\
\hline 2016 & 140.68 \\
\hline 2018 & 192.45 \\
\hline 2019 & 204 \\
\hline
\end{tabular}

\begin{tabular}{|l|l|}
\hline stand international & Acronyms \\
\hline $4 G$ & $4^{\text {th }}$ Generation \\
\hline 5 G & $5^{\text {th }}$ Generation \\
\hline AAA & Authentication, Authorization, Accounting \\
\hline APDV & Application Protocol Data Unit \\
\hline API & Application Programing Interface \\
\hline ARM & Advanced RISC Machine \\
\hline AV & Antivirus \\
\hline B2B & Business to Business \\
\hline B2C & Business to Customer \\
\hline BTS & Base Transceiver Station \\
\hline CC & Cloud Computing \\
\hline CSP & Cloud Service Provider \\
\hline EC2 & Elastic Compute Cloud \\
\hline GPS & Global Positioning System \\
\hline HA & Home Agent \\
\hline IaaS & Infrastructure as a Service \\
\hline IA & Integrated Authenticated \\
\hline ID & Identifier \\
\hline IMERA & Mobile Interaction in Augmented Reality Environment \\
\hline ISP & Internet Service Provider \\
\hline IRNA & Intelligent Radio Network Access \\
\hline JME & Java ME, a Java Platform \\
\hline LBS & Location Trusted Server \\
\hline LTE & Long Term Evolution \\
\hline LTS & Location Trusted Server \\
\hline
\end{tabular}




\begin{tabular}{|l|l|}
\hline MAUI & Memory Arithmetic Unit and Interface \\
\hline MC & Mobile Computing \\
\hline MCC & Mobile Cloud Computing \\
\hline MSC & Mobile Service Cloud \\
\hline P2P & Peer to Peer \\
\hline PaaS & Platform as a Service \\
\hline QoS & Quality of Service \\
\hline RACE & Resource-Aware Collaborative \\
\hline REST & Representational State Transfer \\
\hline RFS & Random File Protocol \\
\hline S3 & Simple Storage Service \\
\hline SaaS & Software as a Service \\
\hline SOA & Services oriented architecture \\
\hline SFDC & Sales force dot com \\
\hline TCC & Trust Resource Identifier \\
\hline
\end{tabular}

Mobile cloud computing is simple to signify an organisation where both data stores and information processing occur outside the mobile device. In this Mobile cloud presentations transfer the computing power \& data storage gone since mobile device and hooked on the cloud, collecting the application and mobile computing to just not smart device operators, hence much wider mobile subscriber range.

Mobile cloud computing defines[2]as a creative requirement for mobile devices where through information processing \& storage, mobile computing starts to strange, centralised computing stages in clouds. Such centralised requests are opened by the wireless link based on negative consumers or mobile devices.

Instead, MCC can persist known as a mix of mobile web in addition to cloud computing, the user's largest current mobile access to service and internet implementations. Mobile cloud computing offers mobile users with cloud data processing and storage services. Mobile devices don't want any important structure (like, Central Process Unit, and Memory Storage Capacity) because all complex computing elements can stay in the clouds.

\section{IV.DESIGN OF MOBILE CLOUD COMPUTING}

The design of Mobile Cloud Computing can be shown in Figure 1. Mobile devices are related to mobile network via base stations (e.g. transceiver station, access point or satellite) that create as well as control associates and well-designed network and mobile device interfaces. Information and needs of mobile users (identification and location) are transmitted to central processors to servers linking mobile network services. Based on the home agent and subscribers data stored in databases, mobile network operators can provide services to mobile users as authorization, authentication and accounting. Subscriber requests are delivered via the internet to a cloud. Cloud devices process requests in that cloud to give mobile users equivalent cloud services. These types of services are established by virtualization utility computing models and SOA (like Web, Application, and Database Service). The deep cloud architecture structure may be altered in different environments. This is four Tier architecture in [8] comparing associated cloud computing with grid computing. Instead, SOA is present to allow developers to build. Microsoft.NET requests with the support of APIs and multiple programming models[9].[10] Present a market-oriented cloud generation architecture and[11] recommend a Webbased business services architecture. Coming to the paper mainly motivating cloud computing tier architecture (shown in fig 2). Architecture regularly focuses on demonstrating the cloud computing model's efficiency in meeting user requests.

Mostly, cloud computing is large-scale distributed network system based on the number of servers in data centres. Cloud services are mostly classified based on layers[Fig 2]. In the top layers of this paradigm, Infrastructure as a Service (IaaS), Platform as a Service (PaaS) and SaaS are arranged. 


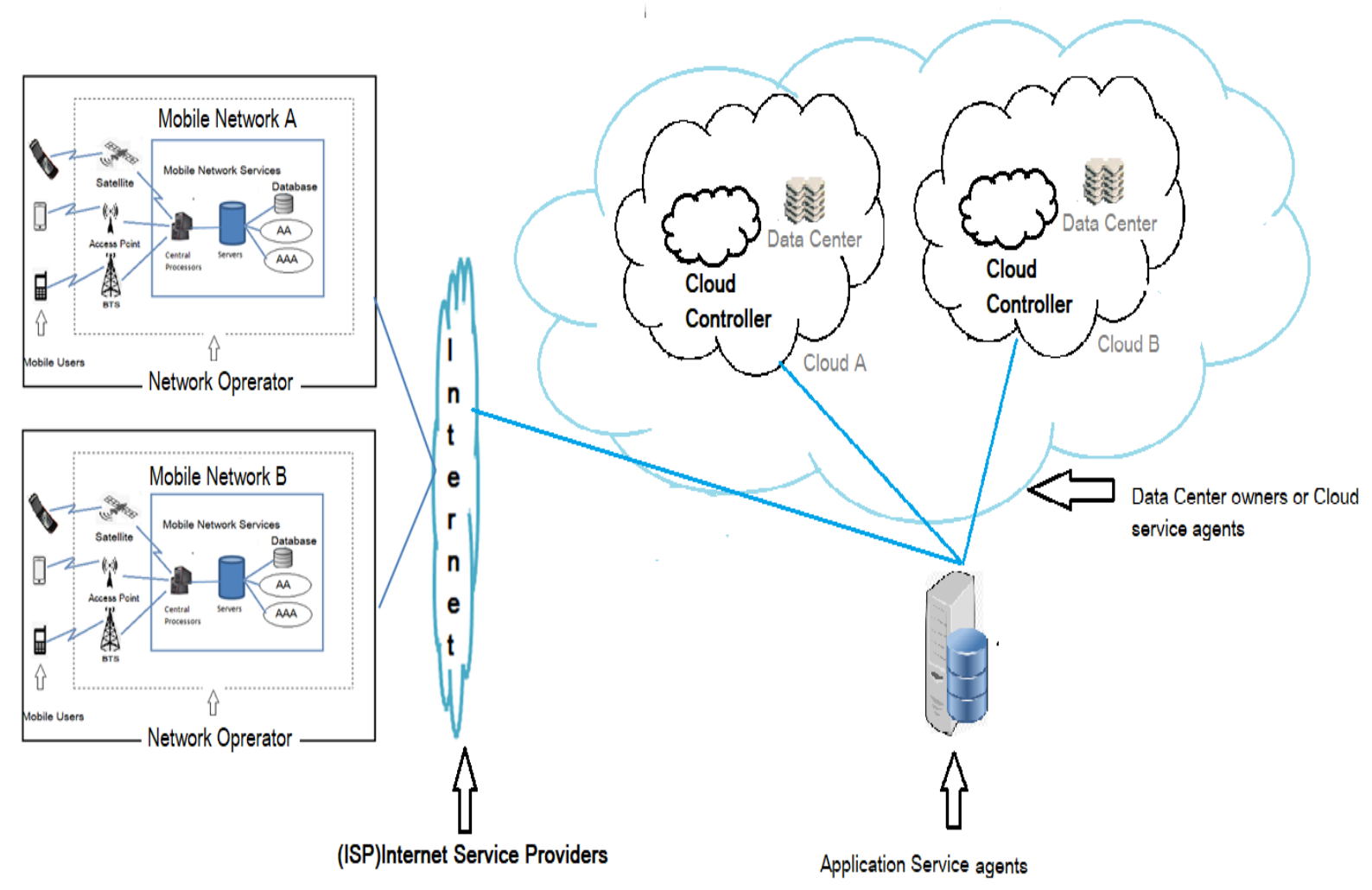

custom applications (For example: Microsoft Azure, Google App Engine etc..).

\section{A.Data Centers layer:}

This layer's purposes construct cloud hardware and infrastructure. In the data centre layer, the amount of servers connecting to high-speed networks to service consumers. Naturally, data centres are built in less needed locations, with a constant high power supply link and low catastrophe risk.

B. Infrastructure as a Service: This layer's objectives construct the data centre layer top. Components used for storage, hardware, servers and networking. This is customer-specific pay per-use. The Customer will save the money since the bill is dependent on the client's resource they choose to use. It's dynamically as needed for infrastructure can be extended (for example: Simple storage service and Amazon Cloud computing)

C. Platform as a Service: This is used for integrated environment for building, testing and deploying
D. Software as a Service: It is distributed applications with detail specifications, the users will access the programme and details remotely over the internet, paying just the kind they choose to use. SFDC is one of SaaS model's innovators. One service provider enables simultaneous file and folder sharing through multiple devices.

In this cloud design architecture, mainly divided into 4 layers as shown in Fig 2. The top layer must be built immediately underneath it. The defined architecture design the customer would use the services flexibly and skillfully, some services might even be calculated as more than one layer. Data storage facilities' definition would be used in IaaS or PaaS. 


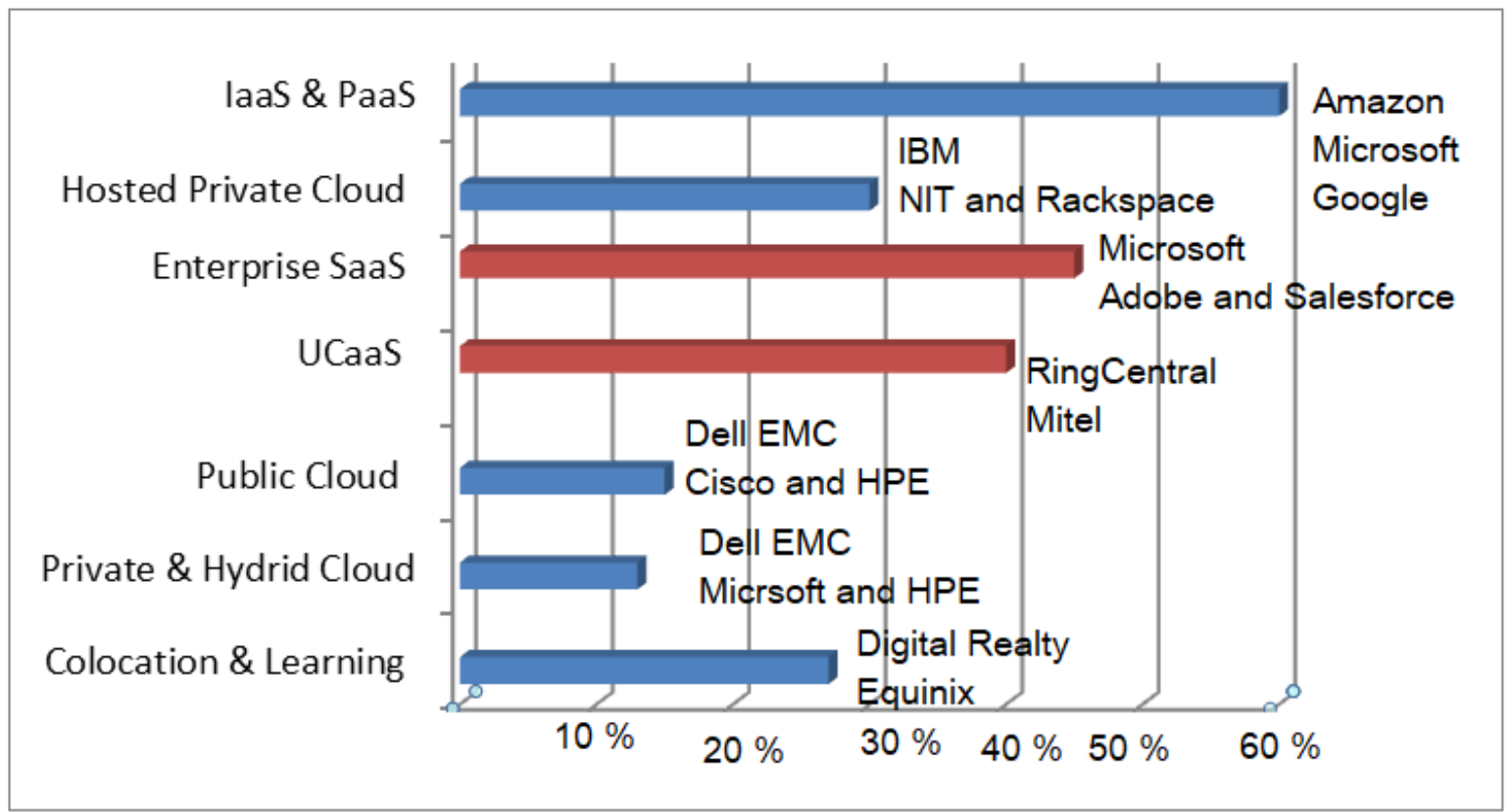

\section{V.BENEFITS OF MOBILE CLOUD COMPUTING}

The mainly cloud computing is identified that capable solution for Mobile computing of many of details for example communication, mobility and portability[13].coming to the cloud can remain used to overcome difficult in mobile computing directing to benefits of Mobile Cloud Computing Network.

A. Data Storage capacity: The huge data on the cloud thru wireless by using Mobile cloud computing. The mainly storage capability is limit for the mobile device. To avoid that limited access and storage data capacity through using MCC.The following examples are Amazon simple storage service[9].An additional example Image exchange which was used for huge storing space in cloud for mobile users[10]. By using this we can easily upload images to the cloud subsequently capturing any time. The couple of years onwards the maximum social network application today using Facebook[12].

B. No Physical Storage and Battery lifetime Extending: The mainly hosted will be everything in the cloud, CC sources across service types and forms reliable and flexible backup and recovery solutions. Although battery is main apprehensions for mobile devices. The amount of resolutions proposed to improve the operation of the CPU and control the screen and disc in an analytical methed.[16,17] to decrease power consumption. But these forms of resolutions alter the structure of mobile devices, owing to the modern hardware that raises prices and is not good for all mobile devices. Computation offloading technique is provided with artefacts to move broad and difficult computing from resourcelimited computers to mobile devices) creative machines (like cloud servers).To prevent long programme processing period on the system and effects will be consumption of large quantity of power. The following example of image processing[20] will minimise mobile device use by $41 \%$. The large-scale statistical analyses indicate that up to 45 percent of the power used can be minimised and many smartphone devices can benefit from assignment relocation and independent processing.

C. Data Reliability Improving: The data management programme on may is a real way to improve stability because of the application and data saved and the amount of computers backup. Remote cloud computing for data protection model built for service providers and consumers alike. For instance, 
cloud prevents exploited and unauthorised distribution[30] and it can be protect video, clip and music of copyrighted digital content. In addition remotely cloud arrange and provide to mobile devices users like virus scanning, code detecting and authentication[11] these are services increase effectiveness of the service.

D. Scalability: Due to adaptive resource provisioning, mobile requests will remain enforced \& scaled to accommodate evolving user requests. It will literally improve and expand an application \& services without/with little reserve utilisation restriction.

E. Ease Incorporation: Several services since dissimilar services provide can remain joined simply thought the cloud \& integration to meet the mobile user'srequests.

\section{VI.MOBILE CLOUD COMPUTING USES:}

Mobile device applications are improvement quickly in universal mobile marketplace. The several Mobile applications have taken the benefits of Mobile cloud computation and The introduced typical characteristic of MCC application.

Table II Request classes of M-Commerce
A. Mobile Commerce or M-commerce: Itis model of application and services became available thru internet assisted mobile devices. Its involves new technologies, services and application fulfill that require mobility. Mobile commerce communications continue to grow for example the purchase and sales of goods \& services, online payment, Bill payment, Online Banking etc. The Mobile commerce classified into various classes containing shopping, Finance and advertising shown table II. While transaction communication face various problems occurs for example security, low internet bandwidth etc. These applications are combined in cloud computation to address the following problems(Low bandwidth, security).The recommends[22] 3G , 4G and $5 \mathrm{G}$ (coming soon) the advantages these generations also cloud computing improve the data processing speed \& safety protected founded on the public and private key techniques. These technique encryption based control and ensure that privacy of users data. 


\begin{tabular}{|l|l|l|}
\hline Application Classes & Type & Example \\
\hline $\begin{array}{l}\text { Mobile Financial } \\
\text { application }\end{array}$ & B2C,B2B & Banks, Brokerage, Firms, Mobile -user fees \\
\hline Mobile Adverting & B2C & $\begin{array}{l}\text { Sending custom made advertisements according to user's } \\
\text { Physical location }\end{array}$ \\
\hline Mobile shopping & B2C,B2B & Locate/Order certain products from mobile terminal \\
\hline
\end{tabular}

B.Mobile Learning or m-Learning:Mobile Learning nothing but learning across the environments with mobile devices at everywhere at any time. In traditional m-learning consume some limits in terms of high cost of network \& devices, Low bandwidth rate.After that cloud founded m-learning are presented to improving these types of issues. By using cloud through big storage capacity \& powerful processing facility improve.The combination m-learning \& cloud computing to improve the message excellence amongst students \& teachers Zhao etal[18]. In this case we used smartphone software for the open basis JavaME and User interface framework and the example of client used jobber, Teams and skype etc. A website develops on google apps Engine we can used for communications between teachers and students any time. This type cloud based m-learning shows that system helps learners right to use learning remotely. The purpose of these applications help the students improves their understanding about the design of mobile cloud computing assistant field knowledge. The developed an teaching tool is founded on cloud calculation to generate a course like image and video processing[41].The new direction in m-learning used smartphone with different software such as AHG clod Note etc.

\section{C.Mobile Healthcare or m-Healthcare:}

By using this application in medical to decrease the traditional medical check-up and supported by mobile devices. Collecting the clinical health records or data, healthcare information researchers and patients simultaneous observing of patient thru mobile telemedicine processes.[27]The following applications in healthcare thru Mobile cloud computing are:

i.

ii.

iii.

iv.

V.

Also The purpose Health cloud information organization system founded on cloud computing \& Mobile devices running Android operational system(AOS)[26].In this example contains 3 services using the Amazon's S3 cloud storing provision to accomplish patient health archives are:

a. cloud storage to Continuous connection

b. Patient health record organization system

c. Image viewing maintenance

In Real-time scheme, A telemedicine homecare organization organization[17][18] is executed in Taiwan to monitoring patient member, Mainly for patients with Diabetes and Hypertension. The propose resolution to protect the consultants health data and collective the privacy of amenities.

\section{The Practical applications and Mobile Gaming:}

The cloud converts a suitable tool to support mobile users upload photos \& videos well good, Tag their relatives and friends in web based network (social network)[15] as Facebook and Twitter and telegrams etc. Mobile cloud computing applications that allows mobile users to share events over the cloud.

Coming to the $\mathrm{m}^{-}$game(Mobile gaming) is revenues generating for service earners.It can totally offload game engine needful huge computing resources: Keyword-built searching, Voice-based probing \& Tag-based searching .In Additionally, The Mobile cloud computing combined services [15] to identify traffic lights. The current services for example: Mobile social network, Bubsy game(cloud) BigTorrent into the cloud[20 \&21].

\section{THE FUTURE RESEARCH DIRECTIONS}

The number of examine works donate to the improvement of mobile could computing, There are numerous open problems $\&$ potential research constraints in the growth mobile devices of Mobile cloud computing.

Low Bandwidth effort:Even the several researchers recommend the effective way of bandwidth distribution. The big apprehensions limitation bandwidth reasons the numeral of mobile \& cloud users remain growing. Coming $4 \mathrm{G}$ and 5G(Fourth and Fifth Generation)network and auspicious skills that overcome too carry a revolution in increasing bandwidth. The current $4 \mathrm{G}$ network support a maximum and coming $5 \mathrm{G}$ network improving such as wandering mobile device coverage and Quality of Service that taken into interpretation in [10].A small cellular base station is called Femtocell and for designed use in small area.[12] Hay systems limited (HSL) combination both femtocells and cloud computing to provide highly efficient, accessible ,secure network and scalable for mobile device operators

Management of Network Access:The management of network not only increases performance of mobile users but also enhances bandwidth usage. The wireless access administration in mobile device communication landscape [23].Rational radio upturns the effectiveness of the range consumption meaningfully, by tolerating unlicensed users. In this method is collaboratingjoined hooked on MCC. The variety can be exploits additional professionallyand therefore 
millions of dollars aimed at the network give can be protected[24].The mobile user in mobile cloud computing necessity to detect the ratio resource accessibility through confirming that the traditional facilities will not stay affected . Quality of Service:In this mobile cloud computing, The operators essential to admission servers placed in cloud and When application intreating services and possessions in the cloud area. The problems might face the mobile users such as cramming due to that limited of wireless bandwidth , Network interruption. There are 2 new investigate directions remain Clone cloud \& Cloudlets that are perhaps to decrease the system interval. Coming to the Clone cloud is the power of cloud computing to mobile devices (smartphones)[25]. It is the increase the speed of running mobile devices services(Smartphone) applications. The whole set of the application in addition to data since mobile devices(smartphone) against the cloud .The limitation of Clone Cloud inability to upgrade negative state and unique resources remotely. Although Cloudlets is trusted \& well associated to the internet thru nearby mobile strategies. If no cloudlets existing adjacent the mobile device might denote to the avoidance mode. How to achieve policies for cloudlets gives to maximum the mobile users involvement whereas minimizing cost. Another problem is cloudlets trust and securities sometimes create fake clodlets to the user information.

Pricing and Standard Interface:The mobile cloud computing contains both Cloud service provider and Mobile service distributor. Both MSP \& CSP in dissimilar services administration, Customers organization, Process of payment in addition prices. How to the price, How to set price and how the price will be separated between different entire like how the customers pay. Coming to the Standard Interface when essential issue the user needs to interact and communicate with cloud. The standard procedure, signaling \& interface for interrelating amongst mobile device user in addition to

cloud ensure that seamless service. In mostly working and In future HTML5 and JSON promising technique to address some type of issues.for example is HTMLS webSockets proposal an interface.

\section{CONCLUSION}

In this paper refer to the Mobile cloud computing is technology of mobile devices now a days and the benefits of mobile computing \& cloud computing. Mobile cloud computing(MCC) is became research oriented and the usage of mobile strategies the amount of and cloud computing by many company's well organization in future will come more applications available with help of new technologies. Most of the companies are on the cloud around $90 \%$. AWS is leading cloud vender $32 \%$ share in the market industry. The mobile cloud market has revenue \$30.7. This paper some of the details provides a summary of MCC which is deals with design of MCC,Benefits of MCC consume been obtainable.
Although more requests supporting by MCC are Mobile Commerce, Mobile Knowledge, Mobile Health care and the practical use and Mobile Gaming have been covered and the wide range of mobile services. At last the future research directions have been defined. As we considered that Mobile cloud computing is vital role now a days and advanced technical world, generating the requirements for finding the solution on this Mobile cloud computing.

\section{REFERENCES}

[1] P. M. Grant \& S. Chen, B. Mulgrew, IEEE Trans. on Neural Networks, vol. 4, pp. 570-578, July 2019 “A clustering technique for digital communications channel equalization using radial basis function networks,".

Mobile Cloud Computing Solution Brief. AEPONA, 2018.

[2] SamiaBouzefrane ,Service Architecture for multienvironment Mobile Cloud Services ,January 2016 International Journal of High Performance Computing and Networking ,342page.

[3] CalheirosRNz, Vecchiola C, Karunamoorthy D, Buyya R. The Aneka platform and QoS-driven resource provisioning for elastic applications on hybrid Clouds. 2017Future Generation Computer Systems, to appear.

[4] Buyya R, Yeo CS, Venugopal S, Broberg J, Brandic I. Cloud computing and emerging IT platforms: vision, hype, and reality for delivering computing as the 5th utility. Journal on Future Generation Computer Systems 2009; 25(6): 599616.

[5] Huang Y, Su H, Sun W, et al. Framework for building a low-cost, scalable, and secured platform for web- delivered business services. IBM Journal of Research and Development 2017; 54(6): 535-548 pages.

[6] Tomasz Imielinski and Henry F. Korth, Rutgers University, New Brunswick, NJ 08903 ,INTRODUCTION TO MOBILE COMPUTING AT\&T Bell Laboratories, 2017,Murray Hill, NJ 07974-0636

[7] A. Acharya and B. Badrinath. Checkpointing distributed applications on mobile computers. In Proc. Third International Conference on Parallel and Distributed Information Systems, Austin, Texas, pages 73-80, September 2016.

[8] Amazon AWS Storage Services Overview A Look at Storage Services Offered by AWS December 2016

[9] Niroshinie Fernando, Seng W. Loke, WennyRahayu Department of Computer Science and Computer Engineering, La Trobe University, Australia .Future Generation Computer Systems Mobile cloud computing: A survey paper Contents lists available at SciVerseScienceDirect 6 June 2013.

[10] S. Perez, Mobile cloud computing: $\$ 9.5$ billion by 2014 , http://exoplanet.eu/ catalog.php, 2010.

[11] [M. Armbrust, A. Fox, R. Griffith, A. Joseph, R. Katz, A. Konwinski, G. Lee, D. Patterson, A. Rabkin, I. Stoica, Above 
the clouds: a Berkeley view of cloud computing, Technical Report UCB/EECS-2009-28, 2009

[12] Foster I, Zhao Y, Raicu I, Lu S. Cloud computing and grid computing 360-degree compared, In Proceed- ings of Workshop on Grid Computing Environments (GCE), 2009

[13] Calheiros RN, Vecchiola C, Karunamoorthy D, Buyya R. The Aneka platform and QoS-driven resource provisioning for elastic applications on hybrid Clouds. Future Generation Computer Sys- tems, to appear.

[14] Gao H, Zhai Y. System design of cloud computing based on mobile learning, In Proceedings of the 3rd International Symposium on Knowledge Acquisition and Modeling (KAM), 2010; 293-242.

[15] Yin C, David B, Chalon R. Use your mobile com- puting devices to learn - Contextual mobile learning system design and case studies, In Proceedings of the 2nd IEEE International Conference on Com- puter Science and Information Technology (ICCSIT), 2009; 440.

[16] Yin C, David B, Chalon R. Use your mobile com- puting devices to learn - Contextual mobile learn- ing system design and case studies, In Proceedings of the 2nd IEEE International Conference on Com- puter Science and Information Technology (ICCSIT), 2009; 440.

[17]E. Walker, W. Brisken, J. Romney, To lease or not to lease from storage clouds, Computer 43 (2010) 44-50

[18] I. Constandache, X. Bao, M. Azizyan, R.R. Choudhury, Did you see bob?: human localization using mobile phones, in: Proceedings of the Sixteenth Annual International Conference on Mobile Computing and Networking, MobiCom'10, ACM, New York, NY, USA, 2010, pp. 149-160.

[19]Zhenyu W, Chunhong Z, Yang J, Hao W. Towards cloud and terminal collaborative mobile social net- work service, In Proceedings of the 2nd IEEE International Conference on Social Computing (SocialCom), 2010; 623.

[20] Kelenyi I, Nurminen JK. CloudTorrent - energy- efficient bittorrent content sharing for mobile devices via cloud services, In Proceedings of the 7th IEEE on Consumer Communications and Networking Confer- ence (CCNC), 2010; 1 .

[21] Yang X, Pan T, Shen J. On 3G mobile e-commerce platform based on cloud computing, 2010; 198-201

[22] Yucek T, Arslan H. A survey of spectrum sens- ing algorithms for cognitive radio applications, In IEEE Communications Surveys \& Tutorials, 2009; 116-130.

[23] Ge F, Lin H, Khajeh A. Cognitive radio rides on the cloud, In Military Communications Conference (MILCOM), $2011 ; 1448$.

[24]Chun BG, Ihm S, Maniatis P, Naik M, Patti A. CloneCloud: elastic execution between mobile device and cloud, In Proceedings of the 6th conference on Computer systems (EuroSys), 2011; 301-314.
[25] Android Operating System: Architecture, Security Challenges and Solutions Working Paper · March 2016 DOI: 10.13140/RG.2.1.4966.3126

[26] Varshney U. Pervasive healthcare and wireless health monitoring. Journal on Mobile Networks and Appli- cations 2007; 12(2-3): 113-127

\section{REFERENCES}

[1]. Abdul Rahman, Ismail \& Memon, Aftab \& Abd Karim, Ahmad. (2013). Relationship between Factors of Construction Resources Affecting Project Cost. Modern Applied Science. 7. 67-75. 10.5539/mas.v7n1p67.

[2]. Dai, Jiukun \& Goodrum, Paul. (2012). Generational differences on craft workers' perceptions of the factors affecting labour productivityThis paper is one of a selection of papers in this Special Issue on Construction Engineering and Management.. Canadian Journal of Civil Engineering. 39. 10.1139/12012-053.

[3]. Dozzi, S. P. \& AbouRizk, S. M. (1993). Productivity in Construction. doi:10.1061/(ASCE)CO.1943-7862.0001138.

[4]. Durdyev, Serdar \& Ismail, Syuhaida. (2012). Role of the construction industry in economic development of Turkmenistan. Energy Education Science and Technology Part A: Energy Science and Research. 29. 883-890.

[5]. Gerek, İ. H., Erdis, E., Mistikoglu, G. \& Usmen, M. (2015). Modelling masonry crew productivity using two artificial neural network techniques. Journal of Civil Engineering and Management. 21(2). 231238. doi:10.3846/13923730.2013.802741

[6]. Hajikazemi, S., Andersen, B. \& Langlo, J. A. (2017). Analyzing electrical installation labour productivity through work sampling. International Journal of Productivity and Performance Management. 66(4). doi:10.1108/IJPPM-06-20160122

[7]. Haas, Carl \& Borcherding, John \& ALLMON, ERIC. (2000). U.S. Construction Labour Productivity Trends, 1970-1998. Journal of Construction Engineering and Management. 126. 10.1061/(ASCE)0733-9364(2000)126:2(97).

[8]. Halligan, D.W., Demsetz, L.A., Brown, J., \& Pace, C.B. (1994). Action-Response Model and Loss of Productivity in Construction. Journal of Construction Engineering \& Management. 120(1). 47-64.

[9]. Liou, F.S. (1986). Work sampling can predict unit rate productivity. Journal of Construction Engineering \& Management. 112(1). 90-103. 
[10]. Liou, F. \& Borcherding, J. D. (1986). Work Sampling Can Predict Unit Rate Productivity. Journal of Construction Engineering and Management. 112(1). 90-103. doi:10.1061/(ASCE)0733-9364(1986)112:1(90).

[11]. Hickson, Brent \& Ellis, Leighton. (2014). Factors affecting Construction Labour Productivity in Trinidad and Tobago. The Journal of the Association of Professional Engineers of Trinidad and Tobago. 42(1). 4-11.

[12]. Khurriah, Hanifatul \& Istifadah, Nurul. (2019). The Role of Infrastructure in Indonesia's Economic Growth. International Journal of Advances in Scientific Research and Engineering. 5. 215-222. 10.31695/IJASRE.2019.33447.

[13]. Momade, Mohammed Hamza \& Shahid, Shamsuddin \& Hainin, Mohd Rosli \& Nashwan, Mohamed. (2019). Construction Labour Productivity: Review of Factors Identified. International Journal of Construction Management. 10.1080/15623599.2019.1627503.

[14]. Ofori, George. (2019). Construction in Developing Countries: Need for New Concepts. Journal of Construction in Developing Countries. 23. 1-6. 10.21315/jcdc2018.23.2.1.

[15]. Pekuri, Aki \& Haapasalo, Harri \& Herrala, Maila. (2011). Productivity and performance management - Managerial practices in the construction industry. International Journal of Performance Measurement. 1. 39-58.

[16]. Robles, G. \& Stifi, Ahmed \& Ponz-Tienda, José \& Gentes, S.. (2014). Labour Productivity in the Construction Industry -Factors Influencing the Spanish Construction Labour Productivity-. International Journal of Civil, Architectural, Structural and Construction Engineering. 8. 9991008.

[17]. Shehata, Mostafa \& El-Gohary, Khaled. (2011). Towards improving construction labour productivity and projects' performance. Alexandria Engineering Journal. 50. 321-330. 10.1016/j.aej.2012.02.001.

[18]. Song, L. \& AbouRizk, S. M. (2008). Measuring and Modeling Labour Productivity Using Historical Data. Journal of Construction Engineering and Management 134(10): 786-794. doi:10.1061/(ASCE)0733-9364(2008)134:10(786)

[19]. Tangen, Stefan. (2005). Demystifying productivity and performance. International Journal of Productivity and Performance Management. 54. 3446. 10.1108/17410400510571437.

[20]. Tsehayae, A. A. \& Robinson Fayek, A. (2014). Identification and comparative analysis of key parameters influencing construction labour productivity in building and industrial projects. Canadian Journal of Civil Engineering. 41. 878891. doi:10.1139/cjce-2014-0031

[21]. Tsehayae, Abraham \& Fayek, Aminah. (2016). Developing and Optimizing Context-Specific Fuzzy Inference System-Based Construction Labour Productivity Models. Journal of Construction Engineering and Management. 142. 04016017. 10.1061/(ASCE)CO.1943-7862.0001127.

[22]. Wells, Jill. (1985). The role of construction in economic growth and development. Habitat International. 9(1). 55-70.

[23]. Westover, Jonathan \& Westover, Andrew \& Westover, L.. (2010). Enhancing long-term worker productivity and performance. International Journal of Productivity and Performance Management. 59. 372-387. 10.1108/17410401011038919.

[24]. Yi, Wen \& Chan, Albert. (2014). Critical Review of Labour Productivity Research in Construction Journals. Journal of Management in Engineering. 30. 214-225. 10.1061/(ASCE)ME.19435479.0000194 . 